\title{
ESTIMATING TURNOVER OF SOIL ORGANIC CARBON FRACTIONS BASED ON RADIOCARBON MEASUREMENTS
}

\author{
Sander Bruun ${ }^{1,2} \cdot$ Johan Six $^{3,4} \bullet$ Lars S Jensen $^{1} \cdot$ Keith Paustian $^{4}$ \\ ABSTRACT. In this paper, we examine 3 different models used to estimate turnover of soil organic carbon (SOC) fractions \\ using radiocarbon measurements: one conventional carbon dating model and two bomb ${ }^{14} \mathrm{C}$ models. One of the bomb ${ }^{14} \mathrm{C}$ \\ models uses an atmospheric ${ }^{14} \mathrm{C}$ record for the period 22,050 BC to AD 2003 and is solved by numerical methods, while the \\ other assumes a constant ${ }^{14} \mathrm{C}$ content of the atmosphere and is solved analytically. The estimates of SOC turnover obtained \\ by the conventional ${ }^{14} \mathrm{C}$ dating model differed substantially from those obtained by the bomb ${ }^{14} \mathrm{C}$ models, which we attribute \\ to the simplifying assumption of the conventional ${ }^{14} \mathrm{C}$ model that the whole $\mathrm{SOC}$ fraction is of the same age. The assumptions \\ underlying the bomb ${ }^{14} \mathrm{C}$ models are more applicable to SOC fractions; therefore, the calculated turnover times are considered \\ to be more reliable. We used Monte Carlo simulations to estimate the uncertainties of the turnover times calculated with the \\ numerically solved ${ }^{14} \mathrm{C}$ model, accounting not only for measurement errors but also for uncertainties introduced from \\ assumptions of constant input and uncertainties in the ${ }^{14} \mathrm{C}$ content of the $\mathrm{CO}_{2}$ assimilated by plants. The resulting uncertainties \\ depend on systematic deviations in the atmospheric ${ }^{14} \mathrm{C}$ record for $\mathrm{SOC}$ fractions with a fast turnover. Therefore, the use of \\ the bomb ${ }^{14} \mathrm{C}$ models can be problematic when SOC fractions with a fast turnover are analyzed, whereas the relative \\ uncertainty of the turnover estimates turned out to be smaller than $30 \%$ when the turnover time of the SOC fractions analyzed \\ was longer than $30 \mathrm{yr}$, and smaller than $15 \%$ when the turnover time was longer than $100 \mathrm{yr}$.
}

\section{INTRODUCTION}

Two distinct theoretical approaches have been taken in the use of radiocarbon to estimate turnover of soil organic carbon (SOC) fractions, namely, the conventional ${ }^{14} \mathrm{C}$ dating model and the bomb ${ }^{14} \mathrm{C}$ model.

According to Scharpenseel and Schiffmann (1977), Paul et al. (1964) first began using ${ }^{14} \mathrm{C}$ dating as a means to study SOC dynamics. Since then, a number of studies have used ${ }^{14} \mathrm{C}$ dating to estimate the turnover or mean residence time of SOC fractions (Martel and Paul 1974; Jenkinson and Rayner 1977; Gilet-Blein et al. 1980; Anderson and Paul 1984; Bol et al. 1999). However, the determination of the turnover time in these studies relies on the theory developed for age determination of archaeological samples, with the prerequisite that the whole sample is of the same age (Libby 1952). This is probably true for the layers of peat soils (Geyh et al. 1971), but obviously not for SOC fractions in general. Therefore, conventional ${ }^{14} \mathrm{C}$ dating leads to biased turnover estimates of SOC fractions. Some of the above-mentioned authors have therefore introduced the terms "the apparent mean residence time" or "equivalent age" for the values obtained. However, interpretation of these values remains difficult (Perrin and Willis 1964; Geyh et al. 1971).

Another model used to estimate SOC turnover relies on the increased level of atmospheric ${ }^{14} \mathrm{C}$ as a consequence of nuclear bomb activity in the 1950s and 1960s (Balesdent 1987; Harkness et al. 1991; Harrison and Broecker 1993; Hsieh 1996; Trumbore 1993; Trumbore et al. 1996; Bird et al. 2002; Chen et al. 2002; Agnelli et al. 2002). Because of the recent appearance of the bomb peak, this method is used to estimate short-term carbon turnover. However, the method may also be used to estimate turnover of more resistant fractions of SOC by taking advantage of the natural decay of ${ }^{14} \mathrm{C}$.

\footnotetext{
${ }^{1}$ Department of Agricultural Sciences, The Royal Veterinary and Agricultural University, Thorvaldsensvej 40, DK-1871 Frederiksberg C, Denmark.

${ }^{2}$ Corresponding author. Email: sab@kvl.dk.

${ }^{3}$ Department of Agronomy and Range Science, University of California-Davis, Davis, California 95616, USA.

${ }^{4}$ Natural Resource Ecology Laboratory, Colorado State University, Fort Collins, Colorado 80523, USA.
} 
We use the term "SOC fractions" for fractions of SOC that can be isolated from the rest of the SOC by physical or chemical fractionation procedures. The SOC fractions can be isolated either from specific horizons or from the whole profile. To be useful in the context of the ${ }^{14} \mathrm{C}$ analyses, the isolated SOC fractions should be as homogeneous as possible with respect to chemical composition and physical protection, and therefore also with respect to turnover (Trumbore and Zheng 1996). Examples of such SOC fractions that have been used in combination with ${ }^{14} \mathrm{C}$ analyses are the hydrolyzable and non-hydrolyzable fractions (e.g. Campbell et al. 1967; Trumbore et al. 1996), different density fractions (e.g. Baisden et al. 2002), and differently sized organomineral fractions (e.g. Anderson and Paul 1984).

The objectives of the current study were to critically analyze the possibilities of estimating turnover of SOC fractions by ${ }^{14} \mathrm{C}$ measurements, and to analyze the uncertainties of the estimates caused by the assumptions underlying the different approaches. We review 3 different theoretical approaches to estimate SOC turnover by ${ }^{14} \mathrm{C}$-based methods, compare the results, and determine the situations in which they can be used to obtain reliable estimates.

\section{METHODS}

\section{The Conventional ${ }^{14} \mathrm{C}$ Dating Model}

The theoretical basis for ${ }^{14} \mathrm{C}$ dating is the exponential decay of ${ }^{14} \mathrm{C}$. In a sample where all the carbon has entered at the same time, the specific activity is described by

$$
A(t)=A_{I}(t) \exp (-\lambda a)
$$

where $A(t)$ is the specific activity of the sample corrected for fractionation during photosynthesis by the ${ }^{13} \mathrm{C}$ content (Stuiver and Polach 1977), $A_{I}(t)$ is the specific activity of the sample when it was formed, $\lambda$ is the decay rate constant of ${ }^{14} \mathrm{C}$, and $a$ is the time since the sample was formed (i.e. its age). Therefore, the age of the sample is

$$
a=\frac{1}{\lambda} \ln \left(\frac{A_{I}(t)}{A(t)}\right)
$$

In standard ${ }^{14} \mathrm{C}$ dating, $A_{a b s}$ is used as the standard ${ }^{14} \mathrm{C}$ content of new material, and the decay rate constant is based on the Libby half-life of ${ }^{14} \mathrm{C}$ (Stuiver and Polach 1977). $A_{a b s}$ is defined as $95 \%$ of the activity in 1950 of an oxalic acid standard, which is estimated to be equal to the atmospheric steady-state level of pre-bomb atmospheric activity. To correct the ${ }^{14} \mathrm{C}$ age for changes in atmospheric ${ }^{14} \mathrm{C}$ content (and therefore $\left.A_{I}(t) \neq A_{a b s}\right),{ }^{14} \mathrm{C}$ calibrations have been constructed coupling real age with ${ }^{14} \mathrm{C}$ age (Stuiver et al. 1998; Damon and Peristykh 2000).

If it is assumed that the measured SOC fraction is in steady-state between inputs and decay, the turnover time $(\tau)$ is equal to the age or the mean residence time of the sample. Therefore, if we assume that the activity of the input is equal to $A_{a b s}$ and that all the carbon in a sample entered the soil at the same time, then the turnover time is

$$
\tau=\frac{1}{\lambda} \ln \left(\frac{A_{a b s}}{A(t)}\right)
$$




\section{The Bomb ${ }^{14} \mathrm{C}$ Model}

Several models have been formulated that use the peak of ${ }^{14} \mathrm{C}$ to estimate turnover of SOC fractions (Balesdent and Guillet 1982; Balesdent 1987; Harkness et al. 1991; Cherkinsky and Brovkin 1993; Hsieh 1993; Trumbore et al. 1996). All the models are fundamentally similar and make use of the same basic assumptions.

The ${ }^{14} \mathrm{C}$ bomb models assume that the turnover of the analyzed SOC fractions is well described by first-order kinetics. As SOC consists of carbon of very varying degradability, this is not a plausible assumption for total SOC. Therefore, the models are applied to SOC fractions. An important feature of these SOC fractions is that the isolated SOC has to be more homogeneous than the total SOC pool with respect to chemical and physical protection. Other basic assumptions in the model are that the inputs to the SOC fractions are constant and that the soil $\mathrm{C}$ level is at equilibrium between input and decay. Furthermore, we need to know the ${ }^{14} \mathrm{C}$ content of the plant material entering the soil. These values are usually calculated from the atmospheric ${ }^{14} \mathrm{C}$ content at the time of plant growth.

The bomb ${ }^{14} \mathrm{C}$ model can be formulated in both continuous and discrete form. As soils receive continuous inputs of organic matter in the form of litter fall and rhizodeposition, we chose to use the continuous form here. We introduce a distribution, $\varphi(a, t)$, of SOC. This distribution is defined such that $\varphi(a, t) d a$ is the amount of organic carbon in a given fraction of SOC at time $t$, which has entered the soil between $a$ and $a+d a$. Thus, $a$ can be conceived as the age of the organic carbon and $\varphi(a, t)$ as an age distribution. A cohort of SOC of age $a$ must have formed $a$ years ago, i.e. at time $t-a$. Therefore, an assumption of first-order kinetics means that the age distribution of age $a$ at time $t$ is given by

$$
\varphi(a, t)=I(t-a) \exp (-k a)
$$

where $I(t)=\varphi(0, t)$ denotes the rate with which new material enters the SOC fraction (the input) at time $t$, and $k$ is the first-order decay constant for the SOC fraction.

By similar arguments to the above and by considering the exponential decay of ${ }^{14} \mathrm{C}$, the specific activity $[A(a, t)]$ of a cohort of SOC of age $a$ at time $t$ is given by

$$
A(a, t)=A_{I}(t-a) \exp (-\lambda a)
$$

where $A_{I}(t)=A(0, t)$ is the specific activity of new material at time $t$, and $\lambda$ is the decay constant of ${ }^{14} \mathrm{C}$. This equation assumes that no isotopic fractionation occurs during the decomposition process.

As $\varphi(a, t) d a$ is the amount of SOC in the fraction of ages $a$ to $a+d a, \varphi(a, t) d a A(a, t)$ is the activity of ${ }^{14} \mathrm{C}$ in the same age interval. Therefore, the specific activity of the whole SOC fraction is given by

$$
A(t)=\frac{\int_{0}^{\infty} \varphi(a, t) A(a, t) d a}{\int_{0}^{\infty} \varphi(a, t) d a}
$$

Insertion of Equation 4 and Equation 5 into Equation 6 leads to 


$$
A(t)=\frac{\int_{0}^{\infty} I(t-a) \exp [-(k+\lambda) a] A_{I}(t-a) d a}{\int_{0}^{\infty} I(t-a) \exp (-k a) d a}
$$

Defining the standardized input history as $i(t)=I(t) / \bar{I}$, where $\bar{I}$ is the average input to the SOC fraction, and inserting this in Equation 7 results in

$$
A(t)=\frac{\int_{0}^{\infty} i(t-a) \exp [-(k+\lambda) a] A_{I}(t-a) d a}{\int_{0}^{\infty} i(t-a) \exp (-k a) d a}
$$

We see that the specific activity is independent of the mean input, but not the input history (i.e. the variation in inputs that has occurred in the past).

To be able to use Equation 8 to estimate $k$, we need to know the standardized input history. However, there is no apparent way to estimate the inputs to SOC fractions. Furthermore, measurements of total litter inputs are generally difficult and rarely performed in long-term studies. If we assume that the input to a SOC fraction is constant, $\varphi(0, t)=I$, and that the soil has reached steady-state, then Equation 4 reduces to

$$
\varphi(a)=I \exp (-k a)
$$

which is the age distribution at steady-state.

To estimate the model parameters $k$ and $I$, we use the measured amount of carbon in the SOC fraction, $C$, and the measured specific activity, $A$. The amount of $C$ can be found by integrating over the age distribution

$$
C=\int_{0}^{\infty} \varphi(a) d a=\int_{0}^{\infty} I \exp (-k a) d a=\frac{I}{k}
$$

whereas the specific activity can be found by insertion into Equation 5

$$
A(t)=k \int_{0}^{\infty} \exp [-(k+\lambda) a] A_{I}(t-a) d a
$$

This is the equation that can be used to estimate the decomposition rate $k$ of SOC fractions by tracking the peak of ${ }^{14} \mathrm{C}$. We call this equation "the bomb ${ }^{14} \mathrm{C}$ equation," and it can only be solved for $k$ by numerical integration and iteration. The value of $k$ can then be used to derive $I$ from Equation 10 and the amount of carbon in the SOC fraction. If several samples have been taken, either at the same or at different points in time, the value of $k$ can be optimized by defining an optimization criterion.

If we assume that the specific activity of inputs to the SOC fraction is constant $\left(A_{I}\right)$, Equation 5 reduces to 


$$
A(a)=A_{I} \exp (-\lambda a)
$$

and the specific activity of the SOC fraction can be found by inserting Equation 12 into Equation 11

$$
A=k A_{I} \int_{0}^{\infty} \exp [-(k+\lambda) a] d a=\frac{A_{I} k}{k+\lambda}
$$

from which $k$ can be isolated

$$
k=\frac{A \lambda}{A_{I}-A}
$$

The assumption of first-order kinetics means that the turnover time can be found as $\tau=k^{-1}$; therefore, if the activity of the inputs is assumed to be equal to $A_{a b s}$, then

$$
\tau=\frac{A_{a b s}-A}{A \lambda}
$$

In most applications of bomb ${ }^{14} \mathrm{C}$ models, the ${ }^{14} \mathrm{C}$ is essentially used as a non-radioactive tracer for estimating turnover on relatively short time scales. However, due to the radioactive decay of ${ }^{14} \mathrm{C}$, these equations can also be used to estimate dynamic parameters of SOC fractions with turnover times that are much longer. However, since the ${ }^{14} \mathrm{C}$ content of the atmosphere has not been constant, the use of the bomb ${ }^{14} \mathrm{C}$ model on $\mathrm{SOC}$ fractions of slow turnover requires that the ${ }^{14} \mathrm{C}$ record extends several thousand years back, which is much longer than has usually been used in applications of the bomb ${ }^{14} \mathrm{C}$ model.

\section{Construction of an Atmospheric ${ }^{14} \mathrm{C}$ Record}

We used the data of Stuiver et al. (1998) to construct a yearly atmospheric ${ }^{14} \mathrm{C}$ record for the Northern Hemisphere by cubic spline interpolation of $\Delta^{14} \mathrm{C}$ values for the period 22,050 BC to AD 1955. For the years between 1955 and 1959, we calculated the average of the values observed for each year in organic materials by Tauber (1967), Vogel (1970), Baxter and Walton (1971), Barrette et al. (1980), Burchuladze et al. (1989), Olsson and Possnert (1992), and Goodsite et al. (2001). For 1959 until 1996, we used the average summer (May to September) atmospheric $\Delta^{14} \mathrm{C}$ values observed by Levin et al. (1985) and Levin and Kromer (1997) for central Europe. To extend the record beyond 1996, we extrapolated the $\Delta^{14} \mathrm{C}$ observations from 1975 to 1996 by an exponential model $\left[\Delta^{14} \mathrm{C}=375 \exp (-0.0621 Y)\right]$ where $Y$ is years after 1975). The resulting complete ${ }^{14} \mathrm{C}$ record is shown in Figure 1.

\section{Comparison of Turnover Estimates by 3 Different Methods}

Thus, there are 3 different methods that can be used to calculate turnover times of SOC fractions based on ${ }^{14} \mathrm{C}$ measurements: 1) the conventional ${ }^{14} \mathrm{C}$ dating model using Equation $3 ; 2$ ) the numerical solution of the bomb ${ }^{14} \mathrm{C}$ equation, by solving for $k$ in Equation 11; and 3) the analytical solution of the bomb ${ }^{14} \mathrm{C}$ equation, Equation 15 .

To compare these different methods, we used all 3 methods to calculate the turnover time corresponding to values of the specific activities of a theoretical sample taken in 2002. 


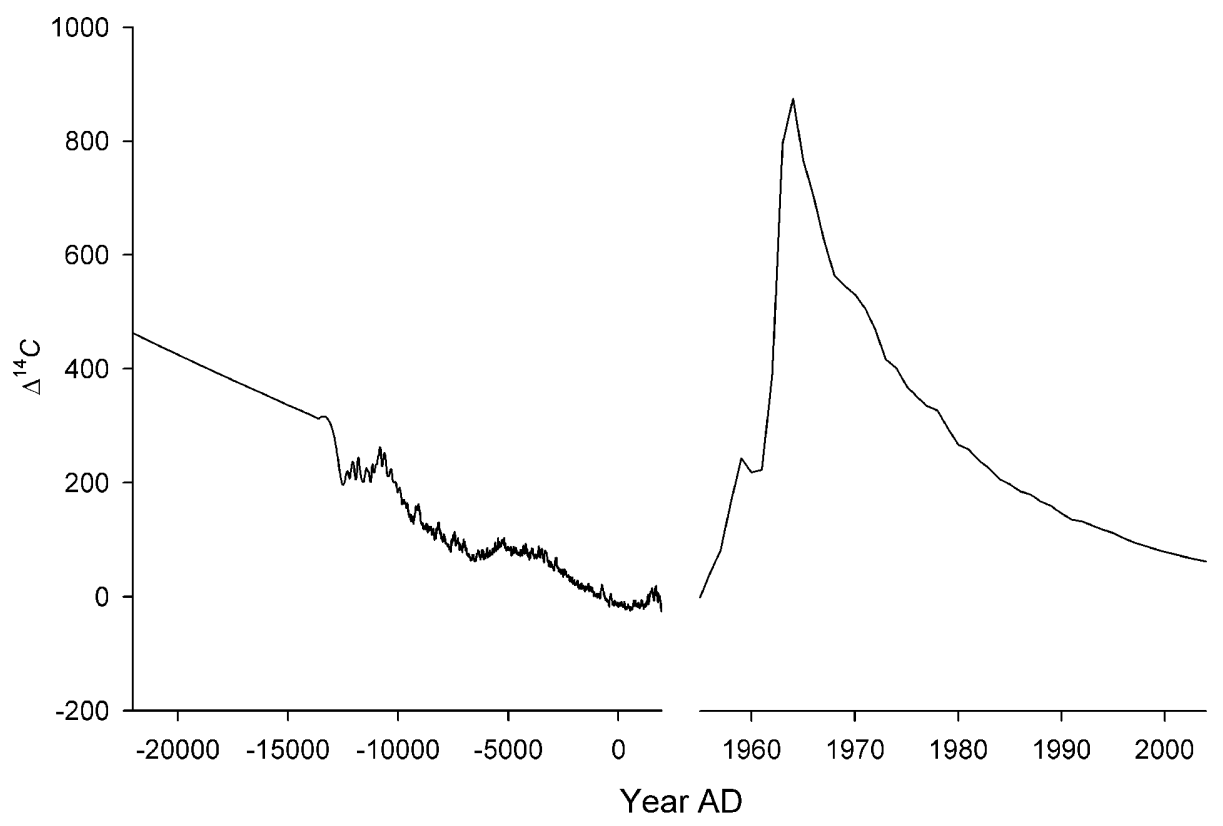

Figure 1 Record of $\Delta{ }^{14} \mathrm{C}$ values used in the models to calculate turnover of SOC fractions. See text for details about the construction of the record.

\section{Assessment of the Uncertainties of the Numerical Bomb ${ }^{14} \mathrm{C}$ Model}

To determine the uncertainties associated with the assumptions of the numerical solution of the bomb ${ }^{14} \mathrm{C}$ equation (Equation 11), we used Monte Carlo simulations. We tested the uncertainties introduced by the assumption of constant inputs and the use of regional data for the ${ }^{14} \mathrm{C}$ content of the specific activity of the inputs entering the SOC fraction. We used 10 different random input histories generated by drawing random numbers from a distribution with an interannual variation similar to that observed in natural ecosystems.

Knapp and Smith (2001) observed that the coefficient of variation (CV) of the interannual net primary production ranged from $3 \%$ to $33 \%$ for different natural ecosystems, with a mean value of $20.4 \%$. Thus, the standardized input histories were generated by drawing random numbers from a normal distribution with a mean of 1 and a standard deviation of 0.204 .

The uncertainty of the ${ }^{14} \mathrm{C}$ content of the inputs was assessed by compiling data from a range of different sources reporting ${ }^{14} \mathrm{C}$ content of different plant-derived materials of known age (Figure 2a). The atmosphere is not completely mixed, and therefore an offset exists between the 2 hemispheres. Furthermore, low and very high latitudes in the Northern Hemisphere also seem to deviate somewhat from the mid-latitudes (Dai and Fan 1986; Kromer et al. 2001). Thus, only samples from sites between $30^{\circ} \mathrm{N}$ and $60^{\circ} \mathrm{N}$ were selected. The values from Baxter and Walton (1971) were originally included in the analysis, but they exhibited considerably more variation than the rest of the data and were therefore excluded. 

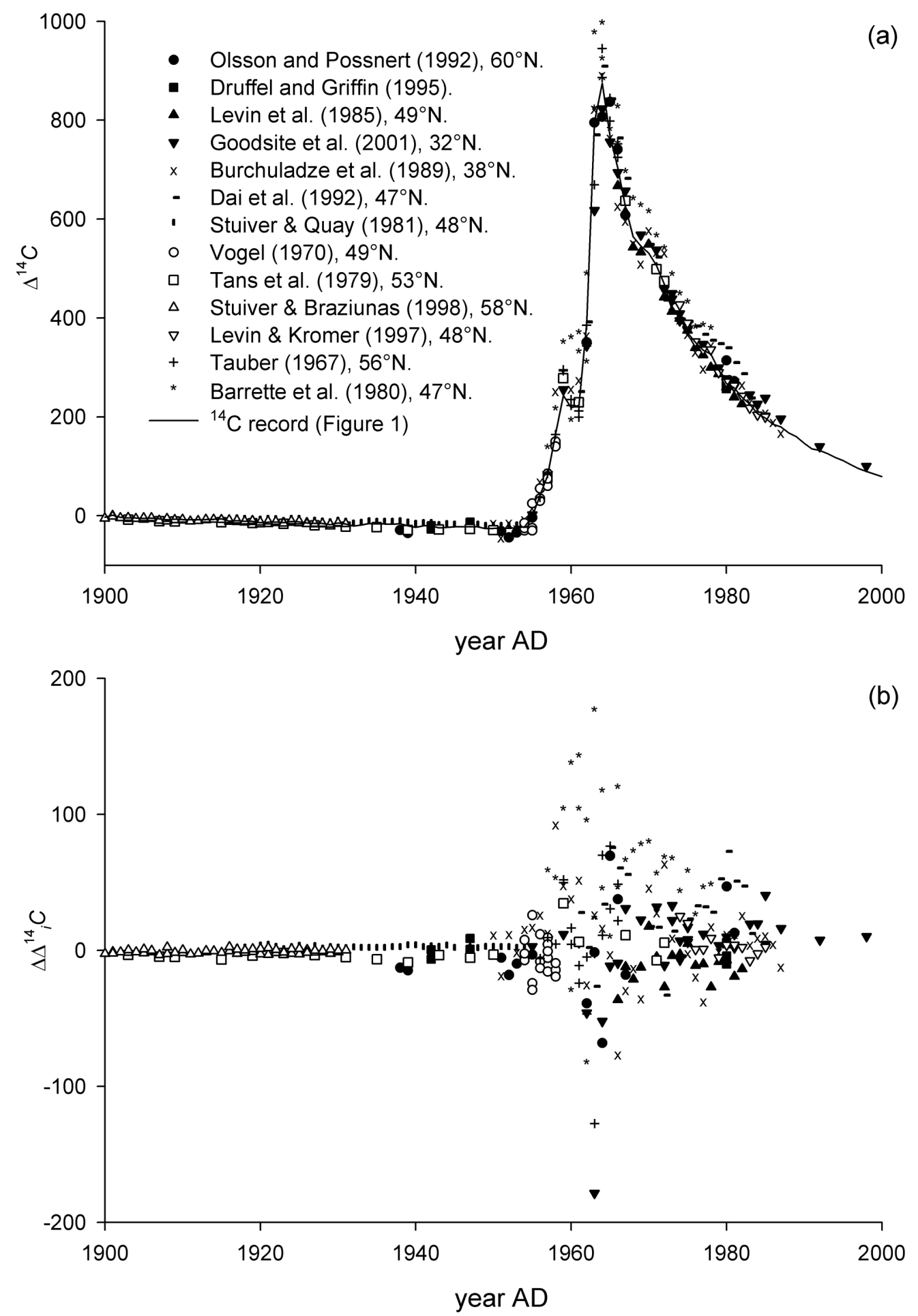

Figure 2 Data used to assess the variation in $\Delta^{14} \mathrm{C}$ values from different sites in the latitudinal range from $30^{\circ} \mathrm{N}$ to $60^{\circ} \mathrm{N}$ : a) $\Delta^{14} \mathrm{C}$ values of different organic materials from published sources, and b) the deviation from the $\Delta^{14} \mathrm{C}$ record: $\Delta \Delta_{i}^{14} \mathrm{C}=$ the values observed for the organic materials - the $\Delta{ }^{14} \mathrm{C}$ value of the ${ }^{14} \mathrm{C}$ record. 
In order to get enough samples to reliably estimate the variation, we calculated the variance in age groups where the variation seemed relatively constant. The standard deviation around the $\Delta^{14} \mathrm{C}$ value in the $j$ th age group was calculated as

$$
\sigma_{j}=\sqrt{\sum_{i=1}^{n_{j}} \frac{\left(\Delta \Delta_{i}^{14} \mathrm{C}\right)^{2}}{n_{j}}}
$$

where $\Delta \Delta_{i}^{14} \mathrm{C}$ is the difference between the $\Delta^{14} \mathrm{C}$ value of the $i$ th sample and the record of the same year and $n_{j}$ is the number of samples in the $j$ th age group. The estimated standard deviation in the different age groups is shown in Table 1.

Table 1 Standard deviation of organic materials (Figure 2) in age groups around the $\Delta^{14} \mathrm{C}$ values from the ${ }^{14} \mathrm{C}$ record (Figure 1). The values are calculated for each age group according to Equation 16.

\begin{tabular}{rc}
\hline $\begin{array}{l}\text { Age group } \\
\text { (year AD) }\end{array}$ & $\begin{array}{l}\sigma_{j} \\
(\%)\end{array}$ \\
\hline-1949 & 2.96 \\
$1950-1954$ & 8.87 \\
$1955-1960$ & 35.5 \\
$1961-1962$ & 60.8 \\
1963 & 106 \\
$1964-1965$ & 49.9 \\
$1966-1969$ & 46.2 \\
$1970-1974$ & 28.6 \\
$1975-1979$ & 22.9 \\
$1980-1983$ & 21.4 \\
$1984-$ & 12.8 \\
\hline
\end{tabular}

The differences between the $\Delta{ }^{14} \mathrm{C}$ value of the sample and of the constructed ${ }^{14} \mathrm{C}$ record $\left(\Delta \Delta_{i}^{14} \mathrm{C}\right)$ are shown in Figure 2b. The variation around the values in the record appears to be random, but it is also evident that the values measured at some sites are systematically higher than at others. This indicates that specific sites may deviate systematically from the ${ }^{14} \mathrm{C}$ record. Based on the estimated variation, we constructed 10 different $\Delta^{14} \mathrm{C}$ activity histories in 2 different ways, one representing random deviations and one representing systematic deviations from the ${ }^{14} \mathrm{C}$ record. The random $\Delta{ }^{14} \mathrm{C}$ histories were generated by drawing 10 random numbers for each year from a standardized normal distribution (i.e. $\mu=0$ and $\sigma=1$ ). These values were multiplied by the standard deviation, $\sigma_{j}$, in Table 1 to obtain a deviation from the ${ }^{14} \mathrm{C}$ record for the year in question. The obtained deviation was added to the $\Delta{ }^{14} \mathrm{C}$ value in the ${ }^{14} \mathrm{C}$ record to obtain a $\Delta{ }^{14} \mathrm{C}$ value for the input that year. The systematic $\Delta^{14} \mathrm{C}$ histories were generated by drawing 10 random numbers from a standardized normal distribution, one for each activity history. This value was multiplied by the standard deviation, $\sigma_{j}$, in Table 1 and again added to the $\Delta{ }^{14} \mathrm{C}$ value in the ${ }^{14} \mathrm{C}$ record to obtain a $\Delta{ }^{14} \mathrm{C}$ value for the input of the year in question.

By combining the input histories with the activity histories, we obtained 2 sets of 10 input/activity histories: 1) 10 input/activity histories with random variation in size of the inputs and random variation in the $\Delta^{14} \mathrm{C}$ values, and 2) 10 input/activity histories with random variation in the size of the 
inputs and systematic variation in the $\Delta^{14} \mathrm{C}$ values. Realistic input/activity histories will probably lie somewhere between these two extremes.

The 2 sets of input/activity histories were used to test the variation in turnover estimates by Monte Carlo simulation, using Equation 8 to calculate the decay rate constant, $k$, for each input/activity history in the 2 sets. This was done for a range of different specific activities of a theoretical SOC fraction in order to determine the relationship between the measured activity of a SOC fraction and the variation in the estimates of $k$.

\section{RESULTS}

\section{Comparison of Different Methods}

The results of the comparison of the different methods for estimating the turnover of SOC fractions are shown in Figure 3. Evidently, the invalid assumptions of the conventional ${ }^{14} \mathrm{C}$ method cause it to produce results that do not agree with the other methods. The analytical solution of the bomb ${ }^{14} \mathrm{C}$ is expected to result in better turnover estimates for all values of the specific activity and is just as easy to calculate. As the analytical solution to the bomb ${ }^{14} \mathrm{C}$ equation encompasses one simplifying assumption more than the numerical solution (constant ${ }^{14} \mathrm{C}$ content of inputs), the numerical solution is expected to be better than the analytical solution. However, as seen in Figure 3, the analytical solution produces results that are relatively close to the numerical solution for SOC samples of slow turnover. Because the ${ }^{14} \mathrm{C}$ record long back in time shows $\Delta^{14} \mathrm{C}$ values considerably larger than $0 \%$ (which is the value corresponding to an input with specific activity of $A_{a b s}$ ), the analytical solution does not approach the numerical when the turnover time becomes very slow. Of course, the analytical method could be improved by using better values than $A_{a b s}$ for the pre-bomb atmospheric ${ }^{14} \mathrm{C}$ activity. However, as this value varies in time, these corrections seem too troublesome compared to finding the numerical solution. This means that the analytical solution can be used when the turnover time of the SOC fraction is sufficiently long and the required precision is not very high.

\section{Uncertainties of Estimates by the Bomb ${ }^{14} \mathrm{C}$ Equation}

Figure 4 shows the relationship between the turnover time and the specific activity of the theoretical samples of 2002. In each figure, there are 10 lines, each corresponding to a different input/activity history. Each of the 10 lines in the figures can be thought of as a possible outcome within the variation in the size of the input and its ${ }^{14} \mathrm{C}$ content. Evidently, the differences between the activities of SOC fractions of the 10 input/activity histories are much more extensive in the case of systematic variation than in cases with random variation in the ${ }^{14} \mathrm{C}$ content. In addition, as the bomb peak has 2 flanks, certain values of the specific activity can correspond to 2 turnover times.

In Figure 5a, the relationship between the average estimated turnover time and the coefficient of variation $(\mathrm{CV})$ of the estimated turnover time is given for the samples taken in 1964, 1966, 1983, and 2002 for the input/activity histories with random variation in ${ }^{14} \mathrm{C}$ content. The coefficient of variation is less than $16 \%$, which is acceptable compared with the uncertainties arising as a consequence of model assumptions, such as the first-order decay of SOC fractions. The uncertainties are quite small over the whole range of turnover times, but are larger for short turnover times than for long.

The results of the random input histories with systematic variation in $\Delta^{14} \mathrm{C}$ values showed much more variability, with CVs larger than 50\% for SOC fractions with turnover times smaller than $15 \mathrm{yr}$ (Figure 5b). However, the estimates are quite reliable even in the case of systematic variation in the 


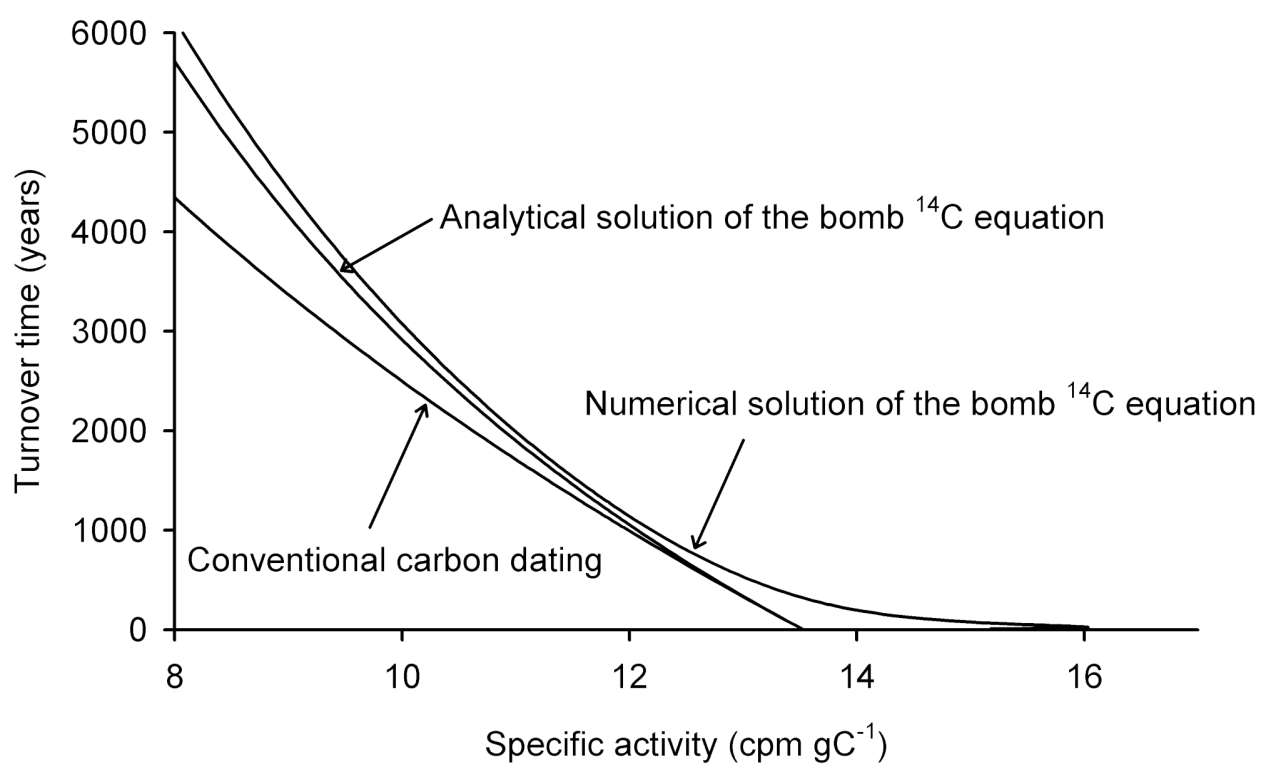

Figure 3 Relationship between the 3 different methods of estimating turnover of SOC fractions: conventional ${ }^{14} \mathrm{C}$ dating (Equation 3), numerical solution of the bomb ${ }^{14} \mathrm{C}$ equation by solving for $k$ in Equation 11 , and the analytical solution of the bomb ${ }^{14} \mathrm{C}$ equation (Equation 15 ).

activity history between the years, as long as the SOC fraction is not turning over too fast. For example, the relative uncertainty is smaller than $30 \%$ if the turnover time of the SOC fraction is longer than $30 \mathrm{yr}$, and smaller than $15 \%$ when the turnover time is longer than $100 \mathrm{yr}$.

\section{DISCUSSION}

Our analysis helps to clarify the consequences of the assumptions underlying the different methods used to estimate kinetic parameters of SOC fractions based on ${ }^{14} \mathrm{C}$ measurements. The conventional ${ }^{14} \mathrm{C}$ dating model effectively assumes that all the carbon in the $\mathrm{SOC}$ fraction is of the same age. As SOC fractions contain carbon that has entered the soil continuously over a long period, this is a questionable assumption. Therefore, the method should only be used in special situations (e.g. the layers of peat soils).

The bomb ${ }^{14} \mathrm{C}$ equation is based on a number of assumptions. First of all, it is assumed that the soil has reached equilibrium between decomposition and inputs. This means that only soils fairly close to equilibrium can be used. The requirement for long periods without changes in climate and vegetational composition may mean that the analysis can only be carried out for soils with native vegetation. Furthermore, because SOC fractions of slow turnover need a long time to reach equilibrium, very slow or inert fractions may be impossible to analyze. The assumption of equilibrium also requires that the inputs are constant and that the ${ }^{14} \mathrm{C}$ content of the inputs are known. However, we allow variations in inputs and deviations from the ${ }^{14} \mathrm{C}$ record as long as these errors average out and therefore do not significantly influence the estimates. Hsieh (1993) showed that large random variation in the inputs influenced estimates of SOC turnover only marginally. We also found only marginal changes in SOC turnover estimates as a result of the variation of the inputs alone (results not shown here). However, variation in the ${ }^{14} \mathrm{C}$ content had a more critical influence on the estimates. Most applications of bomb ${ }^{14} \mathrm{C}$ models combine $\Delta^{14} \mathrm{C}$ values from atmospheric measurements and measurements of organic materials to construct a ${ }^{14} \mathrm{C}$ record with supposedly representative values for the hemisphere in question. Our results show that the uncertainties of the estimates are still quite 

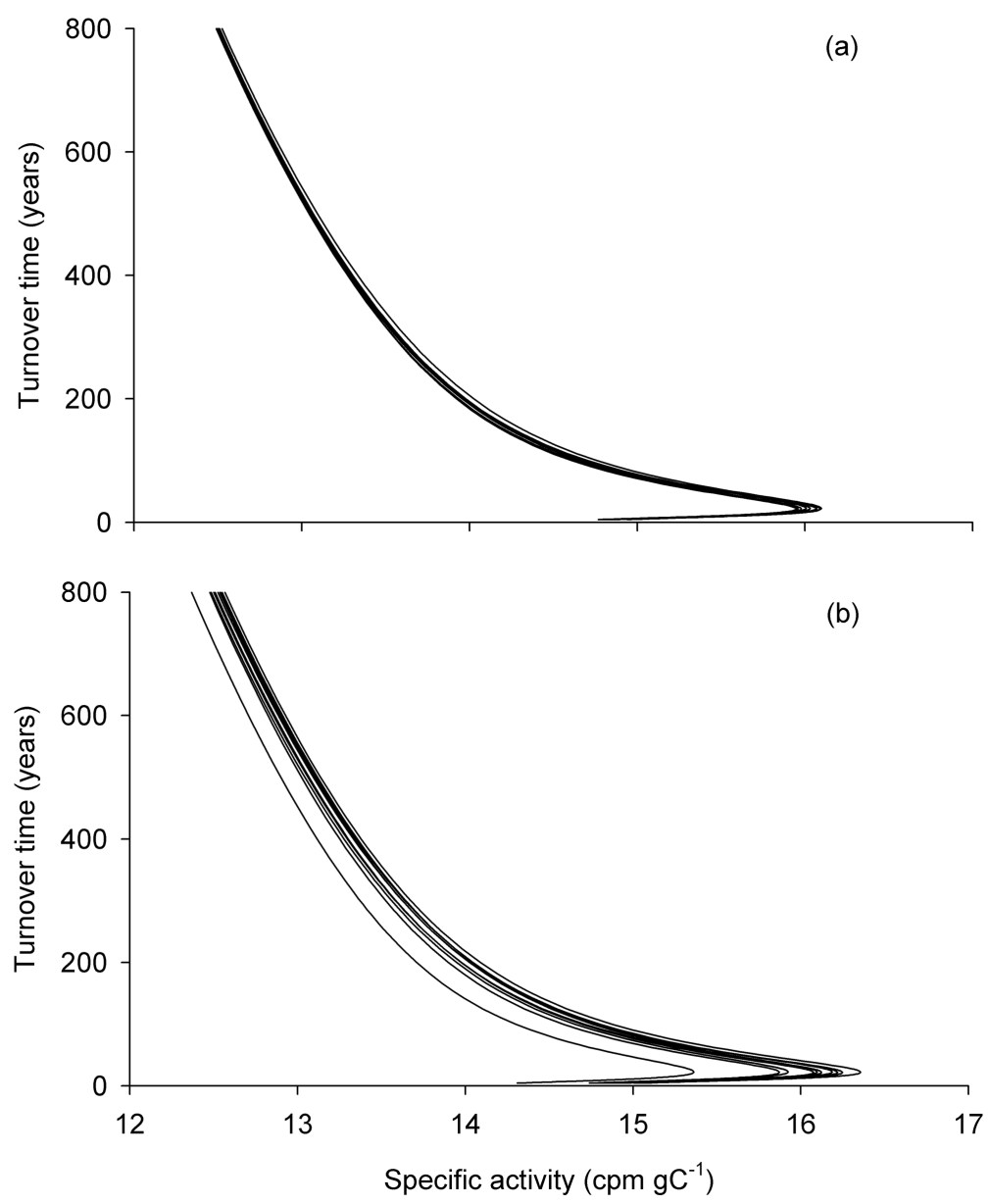

Figure 4 Uncertainties of estimates of the turnover time $(\tau)$ caused by random variation in the inputs, and a) random variation, and b) systematic variation in ${ }^{14} \mathrm{C}$ content from year to year. See text for details.

small if the variation of ${ }^{14} \mathrm{C}$ content around the value in the record can be assumed to be random. However, as the SOC sample has received inputs from vegetation at the same site all the time, the ${ }^{14} \mathrm{C}$ content is likely to be offset from the record in a systematic way. In our assessment of the variability, we even limited the organic materials to latitudes between $30^{\circ} \mathrm{N}$ to $60^{\circ} \mathrm{N}$. If systematic deviations from the record occur, this could influence the estimates of SOC fraction turnover considerably. Thus, the estimates for fast SOC fractions can be uncertain depending on the reliability of the ${ }^{14} \mathrm{C}$ record. If we wish to estimate turnover of fast SOC fractions, values of ${ }^{14} \mathrm{C}$ content of materials from sites closer to the site of sampling should be sought. Furthermore, the estimates of turnover times based on these methods should always be accompanied by an error estimate made by Monte Carlo simulations, based on the uncertainty of the ${ }^{14} \mathrm{C}$ record for the sampling site.

Most applications of bomb ${ }^{14} \mathrm{C}$ models use a ${ }^{14} \mathrm{C}$ record covering only the bomb ${ }^{14} \mathrm{C}$ pulse and thereby assume the $\Delta^{14} \mathrm{C}$ value of the inputs before the pulse is $0 \%$. However, the record from the ${ }^{14} \mathrm{C}$ calibrations shows that this is invalid. We argue that in order to estimate turnover of SOC fractions of slow turnover, the ${ }^{14} \mathrm{C}$ record has to be extended backwards at least 3 or 4 times longer than 

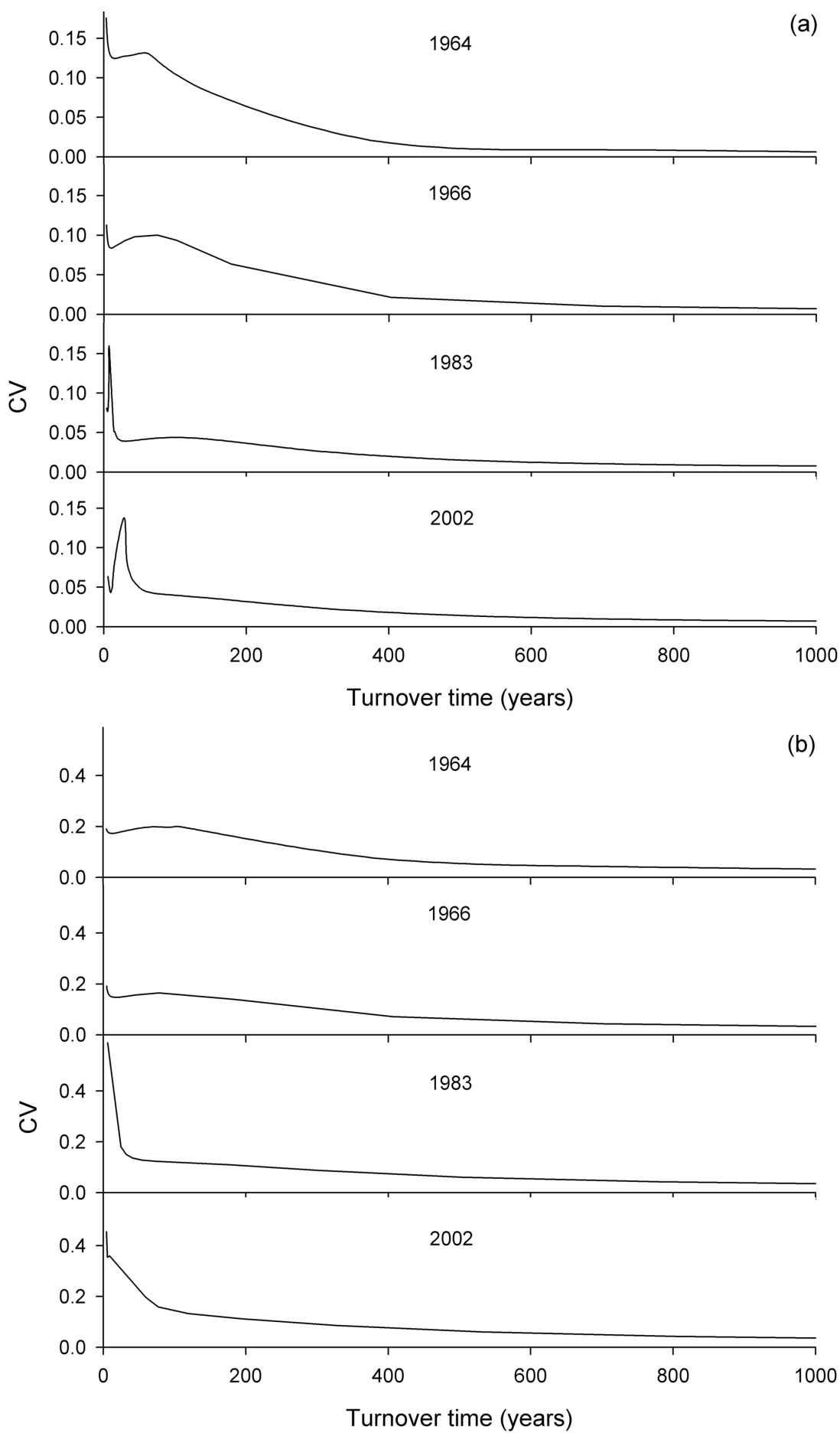

Figure 5 Relationship between average turnover time $(\tau)$ and coefficient of variation $(\mathrm{CV})$ of the turnover time of theoretical samples of SOC fractions from 1964, 1966, 1983, and 2002. The turnover time is estimated for 10 input/activity histories with random variation in the inputs and a) random variation, and b) systematic variation in ${ }^{14} \mathrm{C}$ content from year to year. See text for details. 
the turnover time to be estimated. Since this extended record is used to estimate SOC fractions of slow turnover where the precision of the method is quite high even in the face of systematic errors, the record from the ${ }^{14} \mathrm{C}$ calibrations can quite safely be used to estimate SOC fractions of slow turnover from everywhere in the world.

Another assumption of the bomb ${ }^{14} \mathrm{C}$ models is that the $\mathrm{SOC}$ fractions decay by first-order kinetics. If $\mathrm{SOC}$ fractions are uniform with respect to chemical composition and physical protection, they should have a more uniform decomposition rate, which will enable their description by first-order kinetics. Therefore, researchers have endeavored to isolate organic matter pools consisting of relatively homogeneous material (Trumbore and Zheng 1996; Magid et al. 1996; Sohi et al. 2001). Thus, the application of the theory presented here depends on our ability to obtain fractions that are described well by first-order kinetics.

The bomb ${ }^{14} \mathrm{C}$ model also assumes that no isotopic fractionation occurs during the decay of organic matter. This is of concern because SOC gradually becomes enriched with the stable isotope ${ }^{13} \mathrm{C}$ during decomposition (Balesdent et al. 1993; Balesdent and Mariotti 1996). Balesdent and Mariotti (1996) and Ehleringer et al. (2000) reviewed different hypotheses explaining the ${ }^{13} \mathrm{C}$ enrichment during decomposition but were unable to determine their relative importance. As long as the mechanistic basis of the enrichment has not been elucidated, the hypotheses cannot be included in our models. However, the increase in $\delta^{13} \mathrm{C}$ values is usually less than 4\%o (Balesdent and Mariotti 1996). If all of this enrichment is ascribed to fractionation, this means an additional fractionation for the heavier ${ }^{14} \mathrm{C}$ isotopes of less than $8 \%$, which is very small and on the order of the measurement error.

\section{CONCLUSIONS}

Compared to the numerical solution of the bomb ${ }^{14} \mathrm{C}$ equation, which is assumed to be the best according to the underlying assumptions, the analytical solution is much easier to apply and can be used to obtain results that are sufficiently close to the numerical solution when the SOC fractions analyzed turn over relatively slowly. The uncertainty of the estimates of the numerical solution of the bomb ${ }^{14} \mathrm{C}$ equation is large for SOC fractions with fast turnover due to the uncertainty of the ${ }^{14} \mathrm{C}$ record of litter input at the sampling site, whereas it appears to be negligible when SOC factions turning over relatively slowly are analyzed. For example, the relative uncertainty is smaller than $30 \%$ if the turnover time of the SOC fraction is longer than $30 \mathrm{yr}$, and smaller than $15 \%$ when the turnover time is longer than $100 \mathrm{yr}$.

\section{REFERENCES}

Agnelli A, Trumbore SE, Corti G, Ugolini FC. 2002. The dynamics of organic matter in rock fragments in soil investigated by ${ }^{14} \mathrm{C}$ dating and measurements of ${ }^{13} \mathrm{C}$. European Journal of Soil Science 53(1):147-59.

Anderson DW, Paul EA. 1984. Organo-mineral complexes and their study by radiocarbon dating. Soil Science Society of America Journal 48(2):298-301.

Baisden WT, Amundson R, Cook AC, Brenner DL. 2002. Turnover and storage of $C$ and $N$ in five density fractions from California annual grassland surface soils. Global Biogeochemical Cycles 16(4):1117.

Balesdent J. 1987. The turnover of soil organic fractions estimated by radiocarbon dating. The Science of the Total Environment 62:405-8.

Balesdent J, Girardin C, Mariotti A. 1993. Site-related $\delta^{13} \mathrm{C}$ of tree leaves and soil organic matter in a temper- ate forest. Ecology 74(6):1713-21.

Balesdent J, Guillet B. 1982. Les datations par le ${ }^{14} \mathrm{C}$ des metières organiques des sols. Science du Sol 2:93112.

Balesdent J, Mariotti A. 1996. Measurement of soil organic matter turnover using ${ }^{13} \mathrm{C}$ natural abundance. In: Boutton TW, Yamasaki SI, editors. Mass Spectrometry of Soils. New York: Marcel Dekker. p 83-111.

Barrette L, Lasalle P, Martel Y, Samson C. 1980. Variations of ${ }^{14} \mathrm{C}$ in oats grown from 1957 to 1978 in Québec. Radiocarbon 22(2):410-4.

Baxter MS, Walton A. 1971. Fluctuations of atmospheric carbon-14 concentrations during the past century. Proceedings of the Royal Society of London, Series A 321:105-27.

Bird M, Santrùcková H, Lloyd J, Lawson E. 2002. The 
isotopic composition of soil organic carbon on a northsouth transect in western Canada. European Journal of Soil Science 53(3):393-403.

Bol RA, Harkness DD, Huang Y, Howard DM. 1999. The influence of soil processes on carbon isotope distribution and turnover in the British uplands. European Journal of Soil Science 50(1):41-51.

Burchuladze AA, Chudy M, Eristavi IV, Pagava SV, Povinec P, Sivo A, Togonidze GI. 1989. Anthropogenic ${ }^{14} \mathrm{C}$ variations in atmospheric $\mathrm{CO}_{2}$ and wines. Radiocarbon 31(3):771-6.

Campbell CA, Paul EA, Rennie DA, McCallum KJ. 1967. Applicability of the carbon-dating method of analysis to soil humus studies. Soil Science 104(3): 217-24.

Chen Q, Sun Y, Shen C, Peng S, Yi W, Li Z, Jiang M. 2002. Organic matter turnover rates and $\mathrm{CO}_{2}$ flux from organic matter decomposition of mountain soil profiles in the subtropical area, south China. Catena 49(3):217-29.

Cherkinsky OA, Brovkin VA. 1993. Dynamics of radiocarbon in soils. Radiocarbon 35(3):363-7.

Dai K, Fan CY. 1986. Bomb-produced ${ }^{14} \mathrm{C}$ content in tree rings grown at different latitudes. Radiocarbon 28(2A):346-9.

Dai K, Qian Y, Fan CY. 1992. Bomb-produced ${ }^{14} \mathrm{C}$ in tree rings. Radiocarbon 34(3):753-6.

Damon PE, Peristykh AN. 2000. Radiocarbon calibration and application to geophysics, solar physics, and astrophysics. Radiocarbon 42(1):137-50.

Druffel ERM, Griffin S. 1995. Radiocarbon in tropospheric $\mathrm{CO}_{2}$ and organic materials from selected Northern Hemisphere sites. Radiocarbon 37(3):8838.

Ehleringer JR, Buchmann N, Flanagan LB. 2000. Carbon isotope ratios in belowground carbon cycle processes. Ecological Applications 10(2):412-22.

Geyh MA, Benzler JH, Roeschmann G. 1971. Problems of dating Pleistocene and Holocene soils by radiometric methods. In: Yaalon, editor. Paleopedology. Jerusalem: Israel University Press. p 63-75.

Gilet-Blein N, Marien G, Evin J. 1980. Unreliability of ${ }^{14} \mathrm{C}$ dates from organic matter of soils. Radiocarbon 22(3):919-29.

Goodsite ME, Rom W, Heinemeier J, Lange T, Ooi S, Appleby PG, Shotyk W, van der Knaap WO, Lohse C, Hansen TS. 2001. High-resolution AMS ${ }^{14} \mathrm{C}$ dating of post-bomb peat archives of atmospheric pollutants. Radiocarbon 43(2B):495-515.

Harkness DD, Harrison AF, Bacon PJ. 1991. The potential of bomb- ${ }^{14} \mathrm{C}$ measurements for estimating soil organic matter turnover. In: Wilson WS, editor. Advances in Soil Organic Matter Research: The Impact on Agriculture and the Environment. Colchester: Royal Society of Chemistry. p 239-51.

Harrison K, Broecker W. 1993. A strategy for estimating the impact of $\mathrm{CO}_{2}$ fertilization on soil carbon storage.
Global Biogeochemical Cycles 7(1):69-80.

Hsieh YP. 1993. Radiocarbon signatures of turnover rates in active soil organic carbon pools. Soil Science Society of America Journal 57(4):1020-2.

Hsieh YP. 1996. Soil organic carbon pools of two tropical soils inferred by carbon signatures. Soil Science Society of America Journal 60(4):1117-21.

Jenkinson DS, Rayner JH. 1977. The turnover of soil organic matter in some of the Rothamsted classical experiments. Soil Science 123(5):298-305.

Knapp AK, Smith MD. 2001. Variation among biomes in temporal dynamics of aboveground primary production. Science 291(5503):481-4.

Kromer B, Manning SW, Kuniholm PI, Newton MW, Spurk M, Levin I. 2001. Regional ${ }^{14} \mathrm{CO}_{2}$ offsets in the troposphere: magnitude, mechanisms, and consequences. Science 294(5551):2529-32.

Levin I, Kromer B. 1997. Twenty years of atmospheric ${ }^{14} \mathrm{CO}_{2}$ observations at Schauinsland station, Germany. Radiocarbon 39(2):205-18.

Levin I, Kromer B, Schoch-Fisher H, Bruns M, Münnich M, Berdau D, Vogel JC, Münnich KO. 1985. 25 years of tropospheric ${ }^{14} \mathrm{C}$ observations in central Europe. Radiocarbon 27(1):1-19. (Data online: http:// cdiac.esd.ornl.gov/trends/co2/cent.htm.)

Libby WF. 1952. Radiocarbon Dating. Chicago: University of Chicago Press. 124 p.

Magid J, Gorissen A, Giller K. 1996. In search of the elusive "active" fraction of soil organic matter: three sizedensity fractionation methods for tracing the fate of homogeneously ${ }^{14} \mathrm{C}$-labeled plant materials. Soil Biology and Biochemistry 28(1):89-99.

Martel YA, Paul EA. 1974. The use of radiocarbon dating of organic matter in the study of soil genesis. Soil Science Society of America Proceedings 38(3):501-6.

Olsson IU, Possnert G. $1992 .{ }^{14} \mathrm{C}$ activity in different sections and chemical fractions of oak tree rings, $\mathrm{AD}$ 1938-1981. Radiocarbon 34(3):757-67.

Paul EA, Campbell CA, Rennie DA, McCallum KJ. 1964. Investigations of the dynamics of soil humus utilizing carbon dating techniques. Proceedings of the 8th International Congress of Soil Science 3:201-8.

Perrin RMS, Willis EH. 1964. Dating of humus podzols by residual radiocarbon activity. Nature 202(4928): $165-6$.

Scharpenseel HW, Schiffmann H. 1977. Radiocarbon dating of soils: a review. Zeitschrift für Pflanzenernährung und Bodenkunde 140(2):159-74.

Sohi SP, Mahieu N, Arah JRM, Powlson DS, Madari B, Gaunt JL. 2001. A procedure for isolating soil organic matter fractions suitable for modeling. Soil Science Society of America Journal 65(4):1121-8.

Stuiver M, Braziunas TF. 1998. Anthropogenic and solar components of hemispheric C-14. Geophysical Research Letters 25(3):329-32.

Stuiver M, Polach HA. 1977. Discussion: reporting of ${ }^{14} \mathrm{C}$ data. Radiocarbon 19(3):355-63. 
Stuiver M, Quay PD. 1981. Atmospheric ${ }^{14} \mathrm{C}$ changes resulting from fossil fuel $\mathrm{CO}_{2}$ release and cosmic ray flux variability. Earth and Planetary Science Letters 53:349-62.

Stuiver M, Reimer PJ, Bard E, Beck JW, Burr GS, Hughen KA, Kromer B, McCormac G, van der Plicht J, Spurk M. 1998. IntCa198 radiocarbon age calibration, 24,000-0 cal BP. Radiocarbon 40(3):1041-83. (Data online: http://www.dur.ac.uk/a.r.millard/calibration.html).

Tans PP, de Jong AFM, Mook WG. 1979. Natural atmospheric ${ }^{14} \mathrm{C}$ variation and the Suess effect. Nature 280: 826-8.

Tauber H. 1967. Copenhagen radiocarbon measurements VIII. Geographic variation in atmospheric ${ }^{14} \mathrm{C}$ activ- ity. Radiocarbon 9:246-56.

Trumbore SE. 1993. Comparison of carbon dynamics in tropical and temperate soils using radiocarbon measurements. Global Biogeochemical Cycles 7(2):27590.

Trumbore SE, Chadwick OA, Amundson R. 1996. Rapid exchange between soil carbon and atmospheric carbon dioxide driven by temperature change. Science 272: 393-6.

Trumbore SE, Zheng S. 1996. Comparison of fractionation methods for soil organic matter ${ }^{14} \mathrm{C}$ analysis. Radiocarbon 38(2):219-29.

Vogel JC. 1970. Groningen radiocarbon dates IX. Radiocarbon 12(2):444-71. 